\title{
Prosthetic and orthotic options for lower extremity amputation and reconstruction
}

\author{
Christopher S. Crowe ${ }^{1}$, Kate A. Impastato ${ }^{1}$, Alex C. Donaghy ${ }^{2}$, Caryn Earl ${ }^{3}$, Janna L. Friedly ${ }^{2}$, Kari A. Keys ${ }^{1}$ \\ 'Division of Plastic and Reconstructive Surgery, Department of Surgery, University of Washington School of Medicine, Seattle, WA 98104, \\ USA. \\ ${ }^{2}$ Department of Rehabilitation Medicine, University of Washington School of Medicine, Seattle, WA 98104, USA \\ ${ }^{3}$ Prosthetics and Orthotics Clinic, Harborview Medical Center, Seattle, WA 98109, USA.
}

Correspondence to: Dr. Christopher S. Crowe, Division of Plastic Surgery, Department of Surgery, University of Washington School of Medicine, 7CT73.1 Harborview Medicine Center, 325 9th Avenue, Mailstop \#359796, Seattle, WA 98104, USA.

E-mail: ccrowe2@uw.edu

How to cite this article: Crowe CS, Impastato KA, Donaghy AC, Earl C, Friedly JL, Keys KA. Prosthetic and orthotic options for lower extremity amputation and reconstruction. Plast Aesthet Res 2019;6:4. http://dx.doi.org/10.20517/2347-9264.2018.70

Received: 29 Sep 2018 First Decision: 8 Oct 2018 Revised: 1 Feb 2019 Accepted: 1 Feb 2019 Published: 27 Feb 2019

Science Editor: Matthew L. Iorio Copy Editor: Cai-Hong Wang Production Editor: Huan-Liang Wu

\begin{abstract}
Lower extremity injury and deformity can result from a number of etiologies. Regardless of the underlying cause, the decision to pursue amputation or reconstruction of a lower limb is challenging for both patients and practitioners. This decision is largely dependent on the patient's premorbid health and function, functional goals and preferences, and characteristics and viability of the affected limb. The role of adaptive devices following surgery should never be underestimated. Advances in prostheses and orthoses have provided patients with a wider range of options to consider when deciding between limb reconstruction and amputation. The primary goals of any adaptive device are to improve function, prevent recurrence or ulceration of the defect, and allow for use of conventional footwear and/or clothing. When a lower extremity amputation is indicated, selection of the correct level is of critical importance in order to optimize healing potential and function. Each distinct level has certain inherent prosthetic and orthotic considerations. Likewise, the application of an adaptive device following reconstruction of the lower extremity also has demonstrable benefits and must be tailored to the specific defect and procedure performed. Knowledge of available prosthetic and orthotic options is of considerable importance for the reconstructive surgeon tasked with limb salvage or resurfacing an amputated extremity. This article reviews considerations of various types of lower extremity amputation and reconstruction, and provides a framework for the role of adaptive devices following surgery.
\end{abstract}

Keywords: Prosthesis, orthosis, amputation, reconstruction, rehabilitation, lower extremity

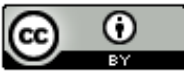

(C) The Author(s) 2019. Open Access This article is licensed under a Creative Commons Attribution 4.0 International License (https://creativecommons.org/licenses/by/4.0/), which permits unrestricted use, sharing, adaptation, distribution and reproduction in any medium or format, for any purpose, even commercially, as long as you give appropriate credit to the original author(s) and the source, provide a link to the Creative Commons license, and indicate if changes were made.

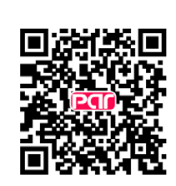




\section{INTRODUCTION}

Lower extremity injuries resulting in dysfunction and deformities can be due to a variety of conditions including congenital abnormalities, trauma, burns, vascular disease, and neuropathic disorders (including diabetes, leprosy, nutritional deficiency, axonal degeneration and demyelinating processes). Regardless of etiology, surgical reconstruction or amputation is often considered to restore function in the extremity when more conservative treatments are unsuccessful ${ }^{[1]}$. The decision about which option is optimal for an individual patient can be challenging. Substantial prior research has compared reconstruction with amputation in terms of function ${ }^{[2,3]}$, quality of life ${ }^{[4,5]}$, and cost-effectiveness ${ }^{[6,7]}$. One of the most important considerations in determining optimal surgical treatment is the prosthetic and orthotic options to restore function after surgery. Recently, advances in prostheses and orthoses have provided patients with a wider range of options to consider when deciding limb reconstruction $v s$. amputation.

Prosthetic restoration following lower extremity amputation has several goals. The first, and arguably the most important, is to reestablish functional mobility and static positioning of the limb. Ambulation using a prosthesis requires increased energy expenditure as the amputation level moves proximally ${ }^{[8]}$. Therefore, a lower limb prosthesis should be designed and fit to minimize this increase in energy expenditure ${ }^{[9,10]}$. Secondly, well-fitting prostheses also serve to prevent breakdown of remaining soft tissue by redistributing compressive force during weight bearing and minimize the amount of shearing force on the skin ${ }^{[11]}$. Lastly, the use of conventional footwear and clothing should be considered when prescribing an adaptive prosthesis, though this may not always be of patient concern. The psychological impact of amputation and its effect on social functioning and identity should not be underestimated ${ }^{[12]}$.

Reconstruction may be pursued when the patient has a reasonable chance at weight bearing and functional ambulation. The decision to reconstruct $v s$. amputate also depends on the neurologic and vascular status of the limb, presence of fracture, risk for ongoing wounds or infection as well as the functional goals of the patient. At times, amputation of the limb may provide a better chance at more fully restoring function in the limb than does limb restoration, and vice versa. The number of surgeries and overall time spent actively rehabilitating is greater for limb salvage with reconstruction as compared to amputation ${ }^{[13]}$. Despite this initial healthcare utilization, the projected lifetime cost of lower extremity reconstruction is considerably lower than amputation ${ }^{[6]}$. The impact of multiple surgeries and subsequent recovery on the overall health of a person should also be considered when deciding between reconstruction $v s$. amputation.

Unlike amputation, which can be divided into categories by level, the reconstruction of the lower limb does not necessarily follow a discrete algorithm in terms of post-reconstruction adaptive devices. Instead, individual defects - their etiology, location, size and depth - must be considered alongside patient factors to determine the need for specific postoperative orthosis. The primary goals of any adaptive device are similarly to improve function, prevent recurrence or ulceration of the defect, and allow for use of conventional footwear and/or clothing.

In this article, we present the surgical considerations of various types of lower extremity amputation and reconstruction, and provide a framework for the role of postoperative adaptive devices including prostheses and orthoses.

\section{LOWER EXTREMITY AMPUTATION}

When amputation of the limb is deemed medically appropriate, selection of the correct level is of critical importance for healing potential and for optimal function. The location of amputation and resulting residual length and limb shape help determine function, energy expenditure necessary for ambulation, and prosthetic options for the amputated limb. Generally speaking, a more distal amputation is more functional as it 
preserves the greatest number of joints and leaves a longer lever arm, allowing for higher torque generation and less daily energy expenditure for ambulation. However, the distal tissue must also have perfusion sufficient to heal and soft tissue coverage must remain durable over the patient's lifetime. In addition, a more proximal amputation may provide better function if the most proximal joint has limited range of motion or function. Thus, the selection of the amputation level can be complex and the decision ideally should be made through a combined effort by the surgeon performing the amputation, the rehabilitation specialist, the patient, and in more complex cases a reconstructive plastic surgeon.

Data regarding the comparative effectiveness of lower limb prostheses is limited and measurable outcomes are not often standardized. Instead, we often rely on the consensus of prosthetic and rehabilitation experts. A review of amputation levels and considerations regarding outcomes and prosthetic options are presented below.

\section{Transmetatarsal amputation}

As its name would suggest, the transmetatarsal amputation (TMA) is performed by transecting between the metatarsal head and base, thus salvaging the mid- and hindfoot ${ }^{[14]}$. TMAs are most often performed in the setting of infection, wounds or deformities of the toes or metatarsal heads. A plantar flap including the transected flexor tendons or a fishmouth incision is used to close the surgical site and provide soft tissue coverage to the distal foot. The precise location of amputation through the transmetatarsal is variable. For instance, the amputation may proceed just proximal to the metatarsal head or through the foot distal to the cuboid and cuneiform bones. A longer residual foot provides additional weight-bearing surface and less muscle imbalance, but the quality of the soft tissue coverage should be considered.

The most common biomechanical complication of a TMA (and other midfoot amputations) is an equinovarus deformity - a resultant imbalance between severed dorsiflexors and intact plantarflexors. Achilles tendon lengthening should therefore be performed at the time of a TMA to reduce risk of equinovarus deformity ${ }^{[15]}$. Moreover, the shortened foot can be unstable during ambulation and the heel may demonstrate excess movement in the patient's footwear. These postoperative factors predispose to complication - with reported rates of delayed wound healing as high as $43 \%-54 \%^{[16,17]}$ and ulceration in as many as $27 \%{ }^{[18]}$. Furthermore, a TMA by definition will reduce the moment arm of the remaining foot, resulting in reduced ankle plantar-flexor torque generation during toe-off. As a result, patients have an inefficient gait without the use of a prosthesis. The appropriate post-operative management of TMAs in terms of dressings (rigid or nonrigid) and weight bearing precautions has not yet been established.

\section{Prosthesis and orthosis for transmetatarsal amputation}

After the transmetatarsal amputation has adequately healed and the patient has progressed to weight bearing, a partial foot prosthesis or orthosis may be prescribed. There are currently several different types of devices available to improve ambulation after partial foot amputation. A total contact in-shoe orthotic with a metatarsal pad molded to the contour of the patient's residual foot is used to better distribute compressive forces along the plantar surface. A toe filler contoured to the footwear is also frequently used to prevent excess motion during ambulation and reduce shearing forces to the plantar surface and posterior heel. However, the use of a full-length shoe with insert and rocker bottom sole has been demonstrated to reduce plantar pressure to a greater degree than a regular shoe with toe filler ${ }^{[19]}$.

The truncated lever arm of the foot after transmetatarsal amputation may be mitigated by using either a carbon-fiber inlay ${ }^{[20]}$ or steel spring ${ }^{[2]]}$ integrated into the orthotic framework, thus providing additional force during terminal stance and helping propel the limb forward. A partial food prosthesis that crosses the ankle joint may also be used to produce additional force for push off and provide stability for patients with impaired balance or strength ${ }^{[22]}$. Devices range from as simple as an in-shoe orthotic to as complex as a tibial 


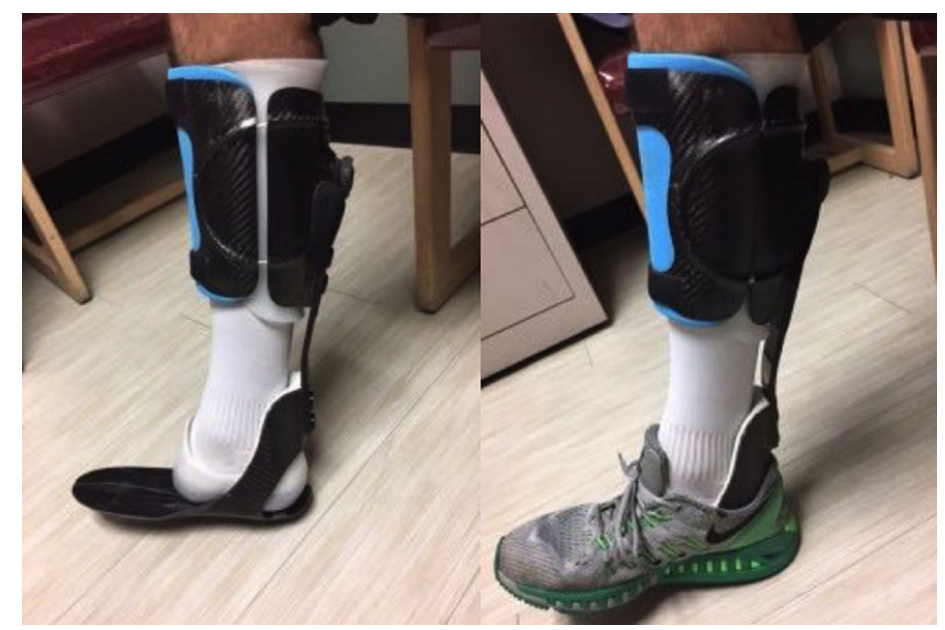

Figure 1. Carbon fiber partial foot prosthesis after Chopart amputation. The patient has remained active and is able run with this device

tubercle height partial foot prosthesis. The correct adaptive device - for any level - depends on patient factors and goals.

\section{Midfoot amputations - Lisfranc and Chopart}

The eponyms Lisfranc and Chopart, both named after their pioneering surgeons, refer to two distinct levels of midfoot amputation. Both of these disarticulations, although less commonly performed, are useful when a paucity of soft tissue in the forefoot prevents successful transmetatarsal amputation or there is significant instability at the respective joint. The Lisfranc amputation disarticulates all five metatarsals from the cuboid or respective cuneiform bone ${ }^{[23]}$. Similar to transmetatarsal amputations, the resultant loss of the peroneal brevis and longus and dorsiflexor insertions leads to unopposed plantarflexion with subsequent equinovarus deformity.

The Chopart amputation excises a greater portion of midfoot and disarticulates the talonavicular and calcaneocuboid joints. This amputation has an even greater propensity for equinovarus deformity ${ }^{[24]}$. There are several methods for rebalancing the foot after such a procedure ${ }^{[25,26]}$, which include Achilles tendon lengthening, gastrocnemius resection, and split anterior tibialis tendon transfer. Preservation of the ankle in most instances is not helpful as the lever arm is short. Historically the utility of traditional midfoot amputations is felt to be low given high rates of subsequent proximal revision amputations ${ }^{[27]}$. The benefit of this level, however, is that it allows the individual to place their foot on the ground, which may be helpful for short distance ambulation. Advances in dynamic ankle foot orthosis (AFO) style partial foot prosthesis have provided improved options for patients with midfoot amputations.

\section{Prosthesis and orthosis for midfoot amputations}

Like transmetatarsal amputations, a custom-fit orthosis and toe filler can be used to stabilize the foot and prevent excess movement of the heel. Mechanisms such as a steel spring or carbon inlay can again be used to counteract the force imbalance between the dorsiflexors and plantarflexors [Figure 1]. Patellar tendonbearing prostheses have been used to unload the short residual foot, although these devices are bulky and lessen the value the extra length afforded by the chosen amputation level. Novel above-ankle prostheses that adequately protect the amputation site and correct varus deformity, while still utilizing the full length of the amputation, have also been described ${ }^{[27]}$.

Preservation of the ankle joint in addition to the use of these inlays can cause a limb length discrepancy between the treated and untreated sides. Thinner, "slipper-like" devices designed to minimize this 
discrepancy provide protection, but do little to correct the equinovarus deformity. More functional devices often require a contralateral shoe lift to correct the length discrepancy.

At our institution, a carbon fiber AFO with an insert or the Phat Brace style orthosis (Bio-mechanical Composites, Des Moines, IA, USA) is commonly employed to provide improved third phase of gait and generate equal step lengths.

\section{Syme amputation}

The Syme amputation, first described by Scottish surgeon James Syme in $1843^{[28]}$, is synonymous with an ankle disarticulation procedure for the treatment of various foot pathologies not amenable to a more distal resection. This amputation is also frequently performed in children with congenital foot deformities. Transection proceeds through the ankle joint and includes the medial and lateral malleoli to achieve an even articular surface. The proximal heel pad is used for coverage. This level of amputation is advantageous as compared to a transtibial amputation as it provides superior gait stability and decreased energy expenditure $^{[29,30]}$. It also provides a greater lever arm length as compared to a more proximal amputation. Postoperative rigid casting allows for partial weight bearing almost immediately post-procedure and early fitting with a prosthesis is often possible. Patients require less physical therapy gait training than with transtibial amputation ${ }^{[31]}$. The retained plantar tissue provides a durable weight-bearing surface and endlimb proprioception remains intact. The residual limb allows for end-bearing so that short distances may be walked without a prosthesis. In patients for whom cognitive or other health factors might preclude prosthesis use, end-bearing can be functionally useful for transfers or standing ADLs. The principle is also true for Chopart and Lisfranc amputations.

\section{Prosthesis and orthosis for Syme amputations}

There are several prosthetic considerations unique to a Syme amputation. The socket of the prosthesis must conform to a bulbous distal residual limb and therefore can be bulky. Generally speaking, two primary types of prosthetic options are available: closed or windowed. Closed prostheses have a "stove-pipe" external appearance as they make use of the residual ankle contour to suspend the prosthesis. Windowed variations allow for a more natural external ankle contour, but must be closed with Velcro straps [Figure 2]. The articulation of the residual limb and adaptive prosthetic foot distally is subject to significant stress. This force must be accounted for and subsequently offloaded by the prosthetic foot. Until recently, sophisticated foot componentry was limited for this level amputation. However, a number of prosthetic manufacturers now provide carbon fiber, energy-storing Syme prosthetic feet. It should be noted that a Syme amputation will almost always lead to a limb length discrepancy as the prosthetic foot must be placed under the residual heel. Therefore, orthosis in the contralateral footwear is needed to correct the limb length discrepancy.

\section{Transtibial amputation}

A transtibial, or below-knee amputation (BKA), is the most common level of amputation. The vast majority of patients undergoing a transtibial amputation will heal their amputation site without complication ${ }^{[32]}$. Patients undergoing a below-knee amputation have a much greater likelihood of ambulating with a prosthesis compared to above-knee amputees, owing to both the mechanical advantages of preserving the knee joint and underlying patient factors predisposing the level of amputation (i.e., often these patients will have greater functional reserve compared to those undergoing above knee amputations). It should be noted, however, that there are situations in which below the knee amputation may not be better than a higher level amputation. For instance, a BKA can predispose to flexion contracture of the knee particularly in patients who are non-ambulatory. Knee flexion contractures can predispose to development of pressure ulcers on the distal residual limb from lying in bed. Patients with spasticity and pre-existing flexion contractures may not be appropriate for BKA, as this may exacerbate the contracture.

The primary surgical consideration of a transtibial amputation relates to the precise anatomic level of bony transection. The ideal length of the residual limb is between 12.5 and $17.5 \mathrm{~cm}$ measured from the 


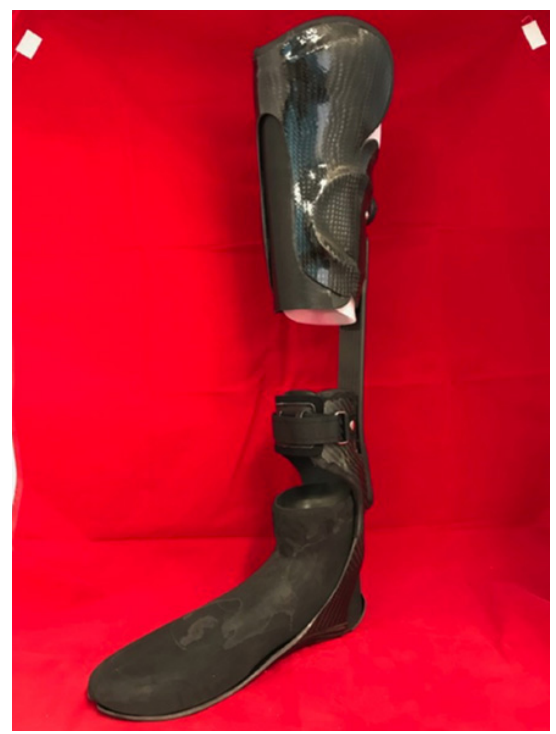

Figure 2. Prosthesis for a congenital Syme amputation with patellar tendon bearing proximal cuff and distal build up due to a short limb

medial joint line. It is frequently cited that a minimum of $5 \mathrm{~cm}$ is required for acceptable function and prosthesis fitting, though this is not always an absolute requirement. The provider and patient must consider the advantages and disadvantages of a short limb with joint preservation $v s$. an above knee amputation. Amputation in the distal third of the leg, however, is often complicated by the paucity of soft tissue coverage for the residual limb. A variety of flaps have been described for coverage of transtibial amputations, although a long posterior, musculocutaneous flap is ideal.

In the case of a traumatic BKA with inadequate local soft tissue for coverage of the residual limb and borderline bone length reconstructive plastic surgeons are often consulted for residual limb coverage for length preservation. Goals of reconstruction are to create a soft, pliable, durable interface with a nonadherent incision (i.e., mobile over bone) in a location $2-8 \mathrm{~cm}$ superior to anterior edge. Positioning the incision line proximal to the distal anterior tibia will prevent the scar from being at the highest pressure, highest friction location when wearing a prosthesis.

Operative management must take into account the skin and soft tissue, muscles, nerves, and bones. First, skin closure should be without tension but not redundant. The more skin surface area available for contact with the prosthetic socket, the less pressure will be applied to each unit area of skin surface. A cylindrical shaped residual limb with ample muscular padding presents fewer skin problems than the bony, atrophic tapered residual limb.

In modern amputations with improved prosthetic interfaces such as gel liners, it is possible for split thickness skin grafts to withstand forces applied by a prosthesis when not adherent to bone. Thus, application of a skin graft over a vascularized muscle bed is viable method of amputation stump reconstruction. However, without at least a fine layer of subcutaneous fat or muscle to absorb shear force, grafts are not as durable and predictably break down. Skin grafting over granulating bone is therefore not advised.

Maximal preservation of functional muscles is essential to provide the limb with strength, size, shape, circulation, and proprioception. Thus, when native muscle remains but has lost its distal insertion, myodesis or myoplasty are often helpful. Myodesis tends to be preferred unless bone quality is poor. 
Care should be taken to identify five nerves intraoperatively: tibial, superficial peroneal, deep peroneal, saphenous, and sural. These should be cut proximally and buried in soft tissue away from the planned incision in order to prevent neuroma formation.

Forces traveling between prosthesis, residual limb, and the remaining body are primarily transmitted through the retained bone in the amputated limb. Managing the edges of severed bone is essential to pain free healing and reduces the chance that bone will erode the overlying skin. The distal corner of tibia should be removed with $45^{\circ}$ anterior beveling and edges should be softened with a saw or rasp. The fibula should be 1-2 $\mathrm{cm}$ shorter than the tibia and beveled to remove the lateral edge.

\section{Prosthesis and orthosis for below-knee amputations}

Below-knee amputation prostheses can be subdivided into the following elements: socket, interface, suspension, shank, and foot/ankle. The prosthetic socket encases the residual limb, and is often classified as either "patellar tendon bearing" - dispersing weight distribution onto several pressure-tolerant areas including patellar tendon - or "total surface bearing," creating a more equal weight distribution throughout the entirety of the socket. In modern practice, most designs are a hybrid of the two ${ }^{[33]}$. The interface describes the material between the socket and the residual limb, which is often a liner. Common interface options include hard-socket with an underlayer of cloth sock, pelite (foam), or silicone. Interface prescriptions take into account maturity and shape of the residual limb, suspension method, patient activity level, patient cognition, upper extremity function, and patient preference.

The mechanical properties of several liner materials - such as tension, compression, shear, and friction have been well studied ${ }^{[34]}$. It has been suggested that stiffer liners are superior for patients with excess soft tissue, while softer, more conformable liners are better for patients with bony prominences ${ }^{[35]}$. Furthermore, liners have an effect on stump moisture and heat retention. Liner materials are generally impermeable to moisture ${ }^{[36]}$ and non-conductive for heat transfer ${ }^{[37]}$, thus contributing to residual limb maceration, dermatitis, hyperhidrosis, and cellulitis. Generally speaking, modern liners make use of roll-on elastomer materials, a more durable and adhesive alternative to foam liners ${ }^{[38]}$. Socks of varying ply are often utilized between the liner and skin and can be added or removed to accommodate for inevitable limb volume changes.

Suspension refers to the method of attachment to the residual limb. Options are numerous and may use anatomic structures to suspend the socket. This may include supracondylar cuffs and brims, may use additional componentry such as neoprene sleeves, thigh corsets, and pin-locks, or utilize pressure differentials as in the case of suction or vacuum assisted suspension. Again, prescriptions take into account anatomical, cognitive, social, and other personal factors. The shank connects the socket to the foot and ankle, and can be categorized as either endo- or exo-skeletal. Endoskeletal pylons are most commonly utilized as they are modular, allowing for modification to height, rotation, and alignment, and also have the potential to be lighter in weight.

There are many prosthetic foot options, which vary in terms of weight, durability, and functionality. Generally, these include solid-ankle cushioned heel, single-axis, multi-axis, and energy-storing/dynamic response, hydraulic, and microprocessor feet. It has been suggested that energy-storing feet provide both vascular and traumatic amputees with a more comfortable stride length and walking speed as compared to traditional solid ankle cushion heel devices ${ }^{[39-41]}$. A single-axis foot may be more useful for less active patients, as it provides an early foot-flat stability and timely transfer of weight onto the supporting prosthetic $^{[42]}$. The disadvantage of these devices is less restraint of dorsiflexion and therefore less stability in late stance phase $\mathrm{e}^{[43,44]}$. Consequently, there is no single prosthetic foot/ankle that provides superior function to all patients, and instead the prosthetic prescription must be tailored to each patient's baseline, projected functional status, and unique needs. 


\section{Knee disarticulation}

Knee disarticulation is a less commonly performed level of amputation with advantages and disadvantages compared to the more proximal above-knee amputation (AKA). Early variations of the through-knee amputation used a soft-tissue closure consisting of only skin and subcutaneous tissue, leaving a fragile envelope prone to bone exposure if dehiscence occurred. Knee disarticulation was greatly improved by use of the gastrocnemius muscle bellies to pad the distal end and thus provide vascularity and additional cushioning to the closure and weight-bearing stump, respectively ${ }^{[45]}$. The knee disarticulation is capable of end bearing, is muscle-balanced in regards to flexion/extension ${ }^{[46]}$ and provides an excellent sitting platform and long lever arm for wheelchair transfers in non-ambulatory patients ${ }^{[47]}$. Leaving the femoral epiphysis intact is important in children, as it will allow for continued longitudinal growth of the femur. In growing patients, the arrest of longitudinal growth is carefully timed so that the prosthetic knee joint may better approximate the length of the unaffected side.

A through knee amputation may pose challenges in regards to a stable and comfortable fit, though this is not necessarily true if the prosthetist is experienced with creating the appropriate socket. This is particularly problematic at the lateral femoral condyle, which may be prone to unbalanced loading and subsequent skin breakdown.

\section{Prosthesis and orthosis for knee disarticulations}

The knee disarticulation results in a bulbous stump end, which is most evident when the femoral condyles are left intact. Choice of liner becomes more important in this circumstance because it has the potential to add even greater bulk to the distal residual limb. Several techniques are available to better accommodate the bulky end - including inner protrusions and medial door openings to allow for passage of the condyles and improved suspension of the prosthetic. The selection of a knee component will be discussed in greater detail below; however, one consideration in knee disarticulation is the position of the prosthetic knee. Analogous to the prosthetic foot/ankle with a Syme amputation, the prosthetic knee center resides more distally than in the contralateral knee following disarticulation, which is more evident when the patient is sitting. Subsequently, the shank portion of the lower leg prosthesis must be shortened to avoid leg-length discrepancy and can cause some challenges in timing of the swing phase of gait on the prosthetic side.

\section{Transfemoral amputation}

The transfemoral, or AKA, is a less desirable level of amputation and is reserved for circumstances in which a below- or through-knee amputation would not suffice to resolve the underlying pathology, allow for enough tibial length for prosthetic fitting, or provide adequate tissue for closure of the residual limb. The transfemoral amputation has been well demonstrated to increase the energy expenditure of ambulation due to alteration of gait mechanics ${ }^{[8]}$. Loss of contact with the tibia and an unopposed abductor mechanism causes the femur to assume an abducted position, thus decreasing the efficiency of gait ${ }^{[48]}$.

Ideally the transfemoral amputation is performed no more than 5-7 cm proximal to the knee joint, leaving as long a lever arm as feasible while still allowing room for a prosthetic knee joint. Early techniques of transfemoral amputation sacrificed the hip adductor muscles, which led to unopposed abduction and flexion. Preservation of the adductor magnus and anchoring to the distal femur improves the position of the femur. Overall, the transfemoral amputation tends to heal quickly and the residual femur has ample soft tissue on all sides, especially when myodesis is pursued. This allows for earlier prosthetic fitting compared to more distal amputations. However, there is less successful prosthetic ambulation in patients undergoing above knee amputations ${ }^{[49]}$.

\section{Prosthesis and orthosis for above knee amputations}

As with below-knee prostheses, socket design, interface, and suspension are necessary considerations in 
Table 1. Medicare Functional Classification Levels

\begin{tabular}{ll}
\hline K-level & \multicolumn{1}{c}{ Definition } \\
\hline 0 & $\begin{array}{l}\text { Does not have the ability or potential to ambulate or transfer safely with or without assistance, and a prosthesis does } \\
\text { not enhance quality of life or mobility } \\
\text { Has the ability or potential to use a prosthesis for transfers or ambulation in level surfaces at a fixed cadence. Typical } \\
\text { of the limited and unlimited household ambulator } \\
\text { Has the ability or potential for ambulation with the ability to transverse low-level environmental barriers such as } \\
\text { curbs, stairs, or uneven surfaces. Typical of the limited community ambulator } \\
\text { Has the ability or potential for ambulation with variable cadence. Typical of the community ambulator who has the } \\
\text { ability to transverse most environmental barriers and may have vocational, therapeutic, or exercise activity that } \\
\text { demands prosthetic use beyond simple locomotion } \\
\text { Has the ability or potential for prosthetic ambulation that exceeds basic ambulation skills, exhibiting high impact, } \\
\text { stress, or energy levels. Typical of the prosthetic demands of the child, active adult, or athlete }\end{array}$ \\
\end{tabular}

above-knee prosthetic prescriptions. Modern socket designs typically have a narrow mediolateral dimension and should encompass the ischium - thus the term "ischial containment" socket. They promote femoral adduction and improve gait efficiency as compared to the more historical "quadrilateral", narrow anteriorposterior design, which did not house the ischium ${ }^{[50]}$. Suspension methods are similar to those with BKAs, and most commonly include suction, pin-locks, or belts/straps.

The primary challenge to the transfemoral amputee prosthetic user is relying on two insensate prosthetic joints during ambulation. Several versions of prosthetic knees exist. The locking knee represents the most simple and stable joint for the wearer, though results in the worst gait efficiency. It is occasionally used early in physical therapy for gait training, for long-term use in patients with high risk of falls, and in minimal ambulators. The knee essentially remains locked in an extended position during all phases of the gait cycle, but can be unlocked to allow transfer between seated and standing positions, and vice versa. A constant friction, single axis knee with stance control is also a relatively stable knee joint, allowing for locked extension when weight bearing and flexing when weight is shifted off the prosthetic. A constant friction, single-axis knee without stance control allows for fixed cadence of gait along a single axis and grants the wearer more control of leg positioning; it is light, durable, and inexpensive, but the user must have adequate hip extensor strength and positional awareness to prevent knee buckling. Four-bar polycentric knees provide no stance control but are inherently more stable than single-axis knees. Additionally, the knee unit is relatively short which may be advantageous for patients with knee disarticulations. Fluid controlled knees allow for a variable cadence of gait via either a hydraulics or pneumatics. These devices are typically prescribed for more active patients with higher-level mobility goals, including variable speeds and/or uneven terrain. Similarly, microprocessor knees utilize hydraulics but with the added feature of computerprogrammed custom settings to regulate knee function. They do not provide active flexion or extension of the knee, but rather finely tune knee stability up to 50-times per second depending on ground forces and joint angle. This is useful to optimize gait efficiency and reduce the amount of falls for the amputee. Obvious disadvantages of microprocessor knees include increased weight and cost, frequent maintenance, and need for daily charging.

The Medicare Functional Classification Levels is a rating system for stratifying an amputee's ability to ambulate. Insurance coverage criteria for knee prostheses were adapted from this system and still remain in effect ${ }^{[51]}$. Levels span Ko, or non-ambulatory, through K4, or high-impact [Table 1]. Constant friction, manual locking, stance-control, and polycentric knees are generally prescribed for K1 and K2 users - those able to ambulate within their own home and those who can overcome minor environmental barriers outside the household. Fluid controlled and microprocessor prosthetics are covered by insurance for those who can exceed the demands of routine locomotion, though there may be utility of these devices for preventing falls in those with lesser levels of ambulation as well. 


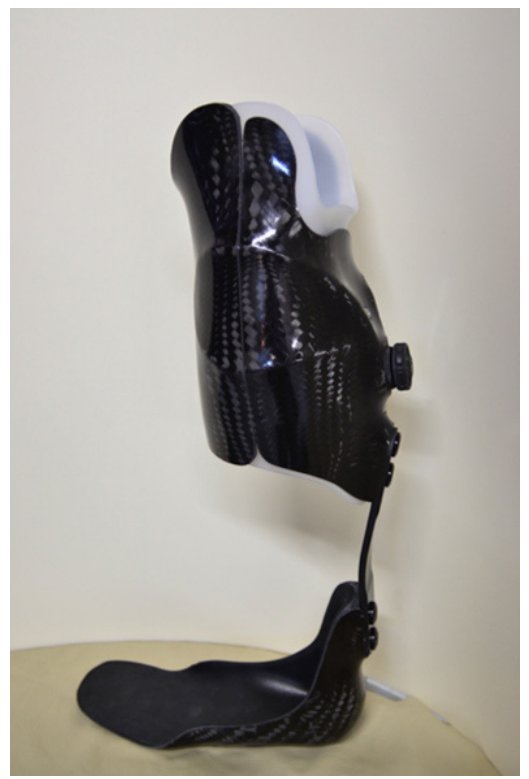

Figure 3. Dynamic ankle foot orthosis with a pretibial shell that allows for offloading of the foot and ankle

\section{LOWER EXTREMITY RECONSTRUCTION}

\section{Goals of reconstruction}

The term "lower extremity reconstruction" consists of a heterogenous grouping of procedures that aim to restore function, bony support, and adjacent soft tissues of a lower extremity defect of deformity. As previously mentioned, reconstruction of the lower extremity attempts to achieve functional weight bearing and independent ambulation. Several scoring systems have been created to predict the potential for limb salvage after traumatic injury ${ }^{[52-57]}$. These systems, however, are unable to accurately predict which patients will eventually undergo an amputation because of their low sensitivities, limiting their usefulness in the clinical setting ${ }^{[58]}$. The decision to perform a lower limb reconstruction is therefore determined based on the specific patient factors and needs, ultimate cost, and social support for rehabilitation.

\section{Orthoses after lower extremity reconstruction}

The primary goal of orthosis in this context is to protect the both remaining and reconstructed soft tissue. One illustrative area of this concept is following reconstruction of the plantar surface of the foot. The heel pad and distal plantar region are characterized by distinct microarchitectural anatomy that withstand compressive and shear forces during the gait cycle. Reconstructed soft tissue with skin grafts, locoregional flaps, and free tissue transfer must also resist these forces. The result of inadequately redistributed pressure is altered gait mechanics, pain in sensate tissue, and recurrent ulceration ${ }^{[99,60]}$. The use of total contact insoles after hindfoot reconstruction has been shown to reduce maximal forces in the heel and improve walking speed $^{[61]}$.

Over the last 10 years, there have been significant advances in offloading ankle/foot orthosis designs that have allowed people with significant lower extremity trauma to participate in higher-level activities. Dynamic AFOs are passive devices that control ankle motion and limit weight bearing through the ankle to address pain, weakness and limitations in range of motion ${ }^{[62-64]}$. Dynamic AFOs are typically made of carbon fiber with a pretibial shell that allows for offloading of the foot and ankle with posterior struts of variable stiffness [Figure 3]. The device stores energy during the stance phase and uses it to generate a more forceful push-off. 
One such device, the Intrepid Dynamic Exoskeletal Orthosis (IDEO), was designed to optimize biomechanics and power after salvage of severely traumatized lower extremities in soldiers ${ }^{[6,66]}$. A systematic review of the IDEO device found that it improved agility, power, and speed compared with non-custom bracing and brace-less rehabilitation ${ }^{[64]}$. Dynamic AFOs can potentially change the post-reconstruction function in pre-morbidly fit patients and provide a rationale for foregoing amputation.

\section{ADVANCEMENTS AND FUTURE DIRECTIONS IN LOWER EXTREMITY PROSTHESIS}

Tremendous improvements in the care and rehabilitation of amputee patients have been made in recent decades. One such advancement is the development of the externally-powered or so-called "bionic" devices. Activation can be microprocessor-controlled (MPC) or driven by myoelectric inputs, whereas function is described as either passive or active. All commercially available lower extremity prosthetic joints are microprocessor-controlled. For these systems, an integrated computer adjusts movement based on real-time calculations of gait-cycle interpretation. The majority of bionic prostheses function passively by means of modulating friction through the joint. For instance, MPC knees increase resistance during stance to mimic eccentric knee extension and decrease resistance during perceived swing to aid toe clearance. MPC knee components may enhance safety and confidence by rapidly adjusting resistance during perceived falls, and may decrease reliance on compensatory gait strategies ${ }^{[67-69]}$.

Myoelectric control systems, which are investigatory for lower extremity prostheses currently, require viable muscle tissue for electrode placement. Signal noise remains a notable challenge with myoelectric devices, compounded by that fact that closed chain kinetics may alter the electrode-residuum contact within the socket. Numerous approaches are being investigated to overcome this, including EMG pattern recognition, intramuscular EMG electrodes, and decomposition of EMG signals ${ }^{[70]}$.

Another limitation of myoelectric devices, especially for lower extremity use, is the unidirectional nature of control; specifically, these systems lack proprioceptive afferent information critical for reflexive and volitional control. This issue has been addressed by surgically creating an agonist-antagonist myoneural interface. This technique involves coaptation of antagonistic lower limb muscle groups within the residual limb, allowing antagonist stretch receptors to better communicate proprioceptive information to the central nervous system. Animal models have demonstrated the potential to communicate graded afferent signals in a manner similar to native muscle architecture ${ }^{[71]}$. A subsequent trial of this method in a single human subject demonstrated objectively improved control over the prosthesis and provided a subjective sense of embodiment of the limb ${ }^{[72]}$.

Notable drawbacks to bionic componentry include increased costs and complexity, as well as the need for charging. Unreliable durability and increased weight are also problematic with myoelectric upper extremity componentry. When considering any prosthetic prescription, one must consider the patient's functional expectations and goals, in addition to their aptitude for complex technology.

\section{CONCLUSION}

Determining whether to pursue amputation or reconstruction of a lower extremity is challenging for patients and practitioners alike - and is dependent on the patient's premorbid health and function, functional goals and preferences in addition to the viability of the limb. The decision to undergo limb reconstruction or amputation is best made with input from surgeon, physical medicine and rehabilitation specialist, and patient in order to achieve the best long-term outcomes. Understanding the functional potential that can be achieved with different levels of amputation and types of and the available prosthetic and orthotic devices is critical to ensure that patients are well-informed of their options [Table 2]. Recent advances in prosthetic and orthotic devices have provided a wider range of options to achieve optimal outcomes. Integration of 
Table 2. Surgical and prosthetic considerations by amputation level

\begin{tabular}{|c|c|c|}
\hline & Surgical considerations & Prosthetic and orthotic considerations \\
\hline Transmetatarsal amputation & $\begin{array}{l}\text { Exact location of transection variable } \\
\text { Closure via plantar flap or fishmouth incision } \\
\text { Consider Achilles lengthening to reduce the risk of } \\
\text { equinovarus deformity }\end{array}$ & $\begin{array}{l}\text { Partial foot prosthesis with toe filler } \\
\text { Carbon-fiber inlay or spring to provide additional } \\
\text { force during terminal stance }\end{array}$ \\
\hline $\begin{array}{l}\text { Midfoot amputation } \\
\text { (e.g., Lisfranc and Chopart) }\end{array}$ & $\begin{array}{l}\text { Level of amputation dependent on joint space transected } \\
\text { Useful when midfoot joint instability is present } \\
\text { Greater propensity for equinovarus deformity and may } \\
\text { require a balancing procedure }\end{array}$ & $\begin{array}{l}\text { Similar prosthetic considerations to } \\
\text { transmetatarsal amputation } \\
\text { Consider contralateral shoe lift if orthotic causes } \\
\text { limb length discrepancy }\end{array}$ \\
\hline Syme amputation & $\begin{array}{l}\text { Provides greater lever arm as compared to transtibial } \\
\text { amputation } \\
\text { Proximal heel pad used for coverage } \\
\text { Partial weight bearing may proceed in early postoperative } \\
\text { period }\end{array}$ & $\begin{array}{l}\text { Limb length discrepancy almost always present } \\
\text { Device must accommodate bulbous distal limb } \\
\text { Prosthetic foot must offload compressive force } \\
\text { on residual limb }\end{array}$ \\
\hline Transtibial amputation & $\begin{array}{l}\text { Location of transection important for both lever arm, } \\
\text { prosthetic accomodation, and soft tissue coverage } \\
\text { Myodesis is preferable if bone quality adequate } \\
\text { Traction neurectomies should be performed in such a way } \\
\text { to prevent neuroma formation }\end{array}$ & $\begin{array}{l}\text { Consider componentry of prosthetic prescription } \\
\text { individually } \\
\text { Ankle joint axis should be chosen based on } \\
\text { patient's level of functionality }\end{array}$ \\
\hline Knee disarticulation & $\begin{array}{l}\text { Generally preferable compared to transfemoral amputation } \\
\text { Gastrocnemius muscle belly may be used to pad distal end } \\
\text { Femoral epiphysis may be left intact in children to allow for } \\
\text { growth }\end{array}$ & $\begin{array}{l}\text { Choice of liner important to accommodate } \\
\text { bulbous residual limb } \\
\text { Position of prosthetic knee lies distal to } \\
\text { contralateral knee, necessitating shortening of } \\
\text { lower leg prosthesis }\end{array}$ \\
\hline Transfemoral amputation & $\begin{array}{l}\text { Soft-tissue envelope generally adequate } \\
\text { Ideally transection occurs no more than } 7 \mathrm{~cm} \text { proximal to } \\
\text { knee joint } \\
\text { Preservation and anchoring of adductor magnus improves } \\
\text { position of femur }\end{array}$ & $\begin{array}{l}\text { Socket narrow in mediolateral dimension } \\
\text { and incorporate ischium to promote femoral } \\
\text { adduction } \\
\text { Choice of prosthetic joints highly dependent on } \\
\text { patient's ambulatory status }\end{array}$ \\
\hline
\end{tabular}

processing systems within prosthetic devices and the advent of myoelectric devices represent promising advancements in the field of prosthetic restoration. Limitations regarding sensibility and proprioception remain a hurdle for emulation of the native limb.

\section{DECLARATIONS}

\section{Authors' contributions}

Literature review: Crowe CS, Impastato KA, Donaghy AC, Earl C

Primary manuscript drafting: Crowe CS, Impastato KA, Donaghy AC

Concept design: Crowe CS, Friedly JL, Keys KA

Substantial manuscript revision: Earl C, Friedly JL, Keys KA

\section{Availability of data and materials}

Not applicable.

\section{Financial support and sponsorship}

None.

\section{Conflicts of interest}

All authors declared that there are no conflicts of interest.

\section{Ethical approval and consent to participate}

Not applicable.

\section{Consent for publication}

Not applicable. 


\section{Copyright}

(C) The Author(s) 2019.

\section{REFERENCES}

1. MacKenzie EJ, Bosse MJ. Kellam JF, Burgess AR, Webb LX, et al. Factors influencing the decision to amputate or reconstruct after highenergy lower extremity trauma. J Trauma 2002;52:641-9.

2. Bosse MJ, MacKenzie EJ, Kellam JF, Burgess AR, Webb LX, et al. An analysis of outcomes of reconstruction or amputation after legthreatening injuries. N Engl J Med 2002;347:1924-31.

3. Russell Esposito E, Stinner DJ, Fergason JR, Wilken JM. Gait biomechanics following lower extremity trauma: amputation vs. reconstruction. Gait Posture 2017;54:167-73.

4. Saddawi-Konefka D, Kim HM, Chung KC. A systematic review of outcomes and complications of reconstruction and amputation for type IIIB and IIIC fractures of the tibia. Plast Reconstr Surg 2002;122:1796-805.

5. Pinzur MS, Pinto MA, Saltzman M, Batista F, Gottschalk F, et al. Health-related quality of life in patients with transtibial amputation and reconstruction with bone bridging of the distal tibia and fibula. Foot Ankle Int 2006;27:907-12.

6. MacKenzie EJ, Jones AS, Bosse MJ, Castillo RC, Pollak AN, et al. Health-care costs associated with amputation or reconstruction of a limb-threatening injury. J Bone Joint Surg Am 2007;89:1685-92.

7. Chung KC, Saddawi-Konefka D, Haase SC, Kaul G. A cost-utility analysis of amputation versus salvage for Gustilo IIIB and IIIC open tibial fractures. Plast Reconstr Surg 2009;124:1965-73.

8. Waters RL, Mulroy S. The energy expenditure of normal and pathologic gait. Gait Posture 1999;9:207-31.

9. Schmalz T, Blumentritt S, Jarasch R. Energy expenditure and biomechanical characteristics of lower limb amputee gait: the influence of prosthetic alignment and different prosthetic components. Gait Posture 2002;16:255-63.

10. Buckley JG, Spence WD, Solomonidis SE. Energy cost of walking: comparison of "intelligent prosthesis" with conventional mechanism. Arch Phys Med Rehabil 1997; 78:330-3.

11. Zhang M. Turner-Smith AR, Roberts VS, Tanner A. Frictional action at lower limb/prosthetic socket interface. Med Eng Phys 1996;18:207-14.

12. Asano M, Rushton P, Miller WC, Deathe BA. Predictors of quality of life among individuals who have a lower limb amputation. Prosthet Orthot Int 2008;32:231-43.

13. Hertel R, Strebel N, Ganz R. Amputation versus reconstruction in traumatic defects of the leg: outcome and costs. J Orthop Trauma 1996;10:223-9.

14. McKittrick LS, McKittrick JB, Risley TS. Transmetatarsal amputation for infection or gangrene in patients with diabetes mellitus. Ann Surg 1949;130:826-40.

15. Garwood CS, Steinberg JS. Soft tissue balancing after partial foot amputations. Clin Podiatr Med Surg 2016;33:99-111.

16. Mueller MJ, Allen BT, Sinacore DR. Incidence of skin breakdown and higher amputation after transmetatarsal amputation: implications for rehabilitation. Arch Phys Med Rehabil 1995;76:50-4.

17. Thomas SR, Perkins JM, Magee TR, Galland RB. Transmetatarsal amputation: an 8-year experience. Ann R Coll Surg Engl 2001;83:164-6.

18. Pollard J, Hamilton GA, Rush SM, Ford LA. Mortality and morbidity after transmetatarsal amputation: retrospective review of 101 cases. J Foot Ankle Surg 2006;45:91-7.

19. Mueller MJ, Strube MJ, Allen BT. Therapeutic footwear can reduce plantar pressures in patients with diabetes and transmetatarsal amputation. Diabetes Care 1997;20:637-41.

20. Tang SF, Chen CP, Chen MJ, Chen WP, Leong CP, et al. Transmetatarsal amputation prosthesis with carbon-fiber plate: enhanced gait function. Am J Phys Med Rehabil 2004;83:124-30.

21. Rommers GM, Diepstraten HJ, Bakker E, Lindeman E. Shoe adaptation after amputation of the II - V phalangeal bones of the foot. Prosthet Orthot Int 2006;30:324-9.

22. Spaulding SE, Chen T, Chou LS. Selection of an above or below-ankle orthosis for individuals with neuropathic partial foot amputation: a pilot study. Prosethet Orthot Int 2012;36:217-24.

23. Lis Franc J. Nouvelle methode operatoire pour l'amputation partielle dans so articulation tarsosmetatarsienne. Paris, France; 1815. Available from: https://play.google.com/books/reader?id=emJtsrU3Sv8C\&hl=en\&pg=GBS.PA3. [Last accessed on 22 Feb 2019]

24. DeCotiis MA. Lisfranc and Chopart amputations. Clin Podriatr Med Surg 2005;22:385-93.

25. Schweinberger MH, Roukis TS. Surgical correction of soft-tissue ankle equinus contracture. Clin Podiatr Med Surg 2008;25:571-85.

26. Schweinberger MH, Roukis TS. Soft-tissue and osseus techniques to balance forefoot and midfoot amputations. Clin Podiatr Med Surg 2008:4:623-39.

27. Krause FG, Aebi H, Lehmann O, Weber M. The "flap-shaft" prosthesis for insensate feet with Chopart or Lisfranc amputations. Foot Ankle Int 2007;28:255-62.

28. Syme J. Amputation at the ankle joint. J Med Sci 1843;2:93.

29. Pinzur MS, Gold J, Schwartz D, Gross N. Energy demands for walking in dysvascular amputees as related to the level of amputation. Orthopedics 1992;15:1033-6; discussion 1036-7.

30. Pinzur MS, Gottschalk F, Smith D, Shanfield S, de Andrade R, et al. Functional outcome of below-knee amputation in peripheral vascular insufficiency. Clin Orthop Relat Res 1993;286:247-9.

31. Pinzur MS. Restoration of walking ability with Syme's ankle disarticulation. Clin Orthop Relat Res 1999;361:71-5

32. Smith DG. Amputation: Preoperative assessment and lower extremity surgical techniques. Foot Ankle Clin 2001;6:271-96.

33. Cifu DX. Braddom's physical medicine \& rehabilitation, 5th ed. Philadelphia, PA: Elsevier Mosby; 2006.

34. Klute GK, Glaister BC, Berge JS. Prosthetic liners for lower limb amputees: a review of the literature. Prosthet Orthot Int 2010;34:146-53. 
35. Sanders JE, Greve JM, Mitchell SB, Zachariah SG. Material properties of commonly-used interface materials and their static coefficients of friction with skin and socks. J Rehabil Res Dev 1998;35:161-76.

36. Hachisuka K, Matsushima Y, Ohmine S, Shitama H, Shinkoda K. Moisture permeability of the total surface bearing prosthetic socket with a silicone liner: is it superior to the patella-tendon bearing prosthetic socket? J UOEH 2001;23:225-32.

37. Klute GK, Rowe GI, Mamishev AV, Ledoux WR. The thermal conductivity of prosthetic sockets and liners. Prosthet Orthot Int 2007;31:292-9.

38. Sanders JE, Nicholson BS, Zachariah SG, Cassisi DV, Karchin A, et al. Testing of elastomeric liners used in limb prosthetics: classification of 25 products by mechanical performance. J Rehabil Res Dev 2004;41:175-86.

39. Powers CM, Torburn L, Perry J, Ayyappa E. Influence of prosthetic foot design on sound limb loading in adults with unilateral below-knee amputations. Arch Phys Med Rehabil 1994;75:825-9.

40. Casillas JM, Dulieu V, Cohen M, Marcer I, Didier JP. Bioenergetic comparison of a new energy-storing foot and SACH foot in traumatic below-knee vascular amputations. Arch Phys Med Rehabil 1995;76:39-44.

41. Snyder RD, Powers CM, Fontaine C, Perry J. The effect of five prosthetic feet on the gait and loading of the sound limb in dysvascular below-knee amputees. J Rehabil Res Dev 1995;32:309-15.

42. Postema K, Hermens HJ, de Vries J, Koopman HF, Eisma WH. Energy storage and release of prosthetic feet. Part 1: biomechanical analysis related to user benefits. Prosthet Orthot Int 1997;21:17-27.

43. Perry J, Boyd LA, Rao SS, Mulroy SJ. Prosthetic weight acceptance mechanics in transtibial amputees wearing the Single Axis, Seattle Lite, and Flex-Foot. IEEE Trans Rehabil Eng 1997;5:283-9.

44. Huang GF, Chou YL, Su FC. Gait analysis and energy consumption of below-knee amputees wearing three different prosthetic feet. Gait Posture 2000;12:162-8.

45. Wagner FW. Management of the diabetic neurotrophic foot. Part II. A classification and treatment program for diabetic, neuropathic, and dysvascular foot problems. Instructional course lectures 1979;28:143-65.

46. Pinzur MS. Bowker JH. Knee disarticulation. Clin Orthop Relat Res 1999;361:23-28.

47. Pinzur MS, Smith DG, Daluga DJ, Osterman H. Selection of patients for through-the-knee amputation. J Bone Joint Surg Am 1988;70:746-50.

48. Gottschalk F. Transfemoral amputation. Biomechanics and surgery. Clin Orthop Relat Res 1999;361:15-22.

49. Volpicelli LJ, Chambers RB, Wagner FW. Ambulation levels of bilateral lower-extremity amputees. Analysis of one hundred and three cases. J Bone Joint Surg Am 1983;65:599-605.

50. Tan J. Practical manual of physical medicine and rehabilitation, 2nd ed. Philadelphia, PA: Elsevier Mosby; 2006. pp. 257-9.

51. Hafner BJ, Smith DG. Differences in function and safety between Medicare Functional Classification Level-2 and -3 transfemoral amputees and influence of prosthetic knee joint control. J Rehabil Res Dev 2009;46:417-33.

52. Helfet DL, Howey T, Sanders R, Johansen K. Limb salvage versus amputation: Preliminary results of Mangled Extremity Severity Score. Clin Orthop 1990;256:80-6.

53. Howe HR Jr, Poole GV Jr, Hansen KJ, Clark T, Plonk GW, Koman LA, Pennell TC. Salvage of lower extremities following combined orthopedic and vascular trauma. A predictive salvage index. Am Surg 1987;53:205-8.

54. Russell WL, Sailors DM, Whittle TB, Fisher DF Jr, Burns RP. Limb salvage versus traumatic amputation: A decision based on a sevenpart predictive index. Ann Surg 1991;213:473-81.

55. McNamara MG, Heckman JD, Corley EG. Severe open fracture of the lower extremity: a retrospective evaluation of Mangled Extremity Severity Score. J Orthop Trauma 1994;8:81-7.

56. Tscherne H, Oestern HJ. A new classification of soft tissue damage in open and closed fractures. Unfallheilkunde 1982;85:111-5.

57. Johansen K, Daines M, Howey T, Helfet D, Hansen ST Jr. Objective criteria accurately predict amputation following extremity trauma. J Trauma 1990;30:568-73.

58. Ong YS, Levin LS. Lower limb salvage in trauma. Plast Reconstr Surg 2010;125:582-8.

59. Chen WP, Ju CW, Tang FT. Effects of total contact insoles on the plantar stress redistribution: a finite element analysis. Clin Biomech 2003; 18:S17-24.

60. Tang SF, Chen CP, Hong WH, Chen HT, Chu NK, et al. Improvement of gait by using orthotic insoles in patients with heel injury who received reconstructive flap operations. Am J Phys Med Rehabil 2003;82:350-6.

61. Chen JT, Tang AC, Hong WH, Tang SF. The effects of heel-elevated total contact insole on rearfoot pressure reduction in heel injury patients who had neurosensory impairment after receiving reconstructive flap operations. Clin Neurol Neurosurg. 2015;129 Suppl 1:S47-52.

62. Koller C, Arch ES. State of the prescription process for dynamic ankle-foot orthoses. Curr Phys Med Rehabil Rep 2018;6:55-61.

63. Wach A, McGrady L, Wang M, Silver-Thorn B. Assessment of mechanical characteristics of ankle-foot orthoses. J Biomech Eng 2018;140.

64. Highsmith MJ, Nelson LM, Carbone NT, Klenow TD, Kahle JT, et al. Outcomes associated with the intrepid dynamic exoskeletal orthosis (IDEO): a systematic review of the literature. Mil Med 2016;181:69-76.

65. Patzkowski JC, Blanck RV, Owens JG, Wilken JM, Blair JA, et al. Can an ankle-foot orthosis change hearts and minds? J Surg Orthop Adv 2011;20:8-18.

66. Blair JA, Patzkowski JC, Blanck RV, Owens JG, Hsu JR, et al. Return to duty after integrated orthotic and rehabilitation initiative. J Orthop Trauma 2014;28:e70-4.

67. Kannenberg A, Zacharias B, Pröbsting E. Benefits of microprocessor prosthetic knees to limited community ambulators: a systematic review. J Rehabil Res Dev 2014;51:1469-95.

68. Sawers, AB, Hafner, BJ. Outcomes associated with the use of microprocessor-controlled prosthetic knees among individuals with unilateral transfemoral limb loss: a systematic review. J Rehab Res Dev 2013;50:273-314.

69. Fuenzalida Squella SA, Kannenberg A, Brandão Benetti Â. Enhancement of a prosthetic knee with a microprocessor-controlled gait phase 
switch reduces falls and improves balance confidence and gait speed in community ambulators with unilateral transfemoral amputation. Prosthet Orthot Int 2018;42:228-35.

70. Kapelner T, Negro F, Aszmann OC, Farina D. Decoding motor unit activity from forearm muscles: perspectives for myoelectric control. IEEE Trans Neural Syst Rehabil Eng 2018;26:244-51.

71. Clites TR, Carty MJ, Srinivasan S, Zorzos AN, Herr HM. A murine model of a novel surgical architecture for proprioceptive muscle feedback and its potential application to control of advanced limb prostheses. J Neural Eng 2017;14:036002.

72. Clites TR, Carty MJ, Ullauri JB, Carney ME, Mooney LM, et al. Proprioception from a neurally controlled lower-extremity prosthesis. Sci Transl Med 2018;10:eaap8373. 